\title{
Analysis of the MOOC Capabilities for Student Training in the Humanities
}

\author{
https://doi.org/10.3991/ijet.v16i22.25071 \\ Sergii Sharov ${ }^{1}(\varpi)$, Oksana Filatova $^{2}$, Valentyna Biliatska $^{3}$, Nadia Yankova ${ }^{4}$ \\ ${ }^{1}$ Dmytro Motornyi Tavria State Agrotechnological University, Melitopol, Ukraine \\ ${ }^{2}$ Admiral Makarov National University of Shipbuilding, Mykolaiv, Ukraine \\ ${ }^{3}$ Dnipro University of Technology, Dnipro, Ukraine \\ ${ }^{4}$ Taras Shevchenko National University of Kyiv, Kyiv, Ukraine \\ sergii.sharovetsatu.edu.ua
}

\begin{abstract}
The article provides a quantitative analysis of the online courses which can be used for student training in the humanities. It is noted that the development of information society influenced the ways of educational activities organization, the process of obtaining new knowledge and competency formation. Under the conditions when online education, blended and distance learning are considerably relevant, massive open online courses are an effective tool for learning and self-development. It was found that training in the humanities plays an important role in personal development of the future specialist. It involves the development of social competence, communication culture, leadership skills, as well as skills of conflict avoidance, teamwork, etc. The effectiveness of training in the humanities is influenced by active teaching methods, interactive technologies, and various means of information and communication technologies. The authors analyzed both the English-language (Coursera, Udemy, Edx) and Ukrainian-language (Prometheus, EdEra, OUM) online platforms. The article provides a quantitative analysis of online courses according to various directions in the humanities on each of the platforms. As of October 2021, we identified 4,769 free and fee-paying courses. The largest number of online courses for training in the humanities is presented on the Udemy platform (4,295 courses), the smallest number - on all Ukrainian-language platforms together (45 courses).
\end{abstract}

Keywords-higher education, distance learning, MOOC, training in the humanities

\section{Introduction}

Today, educational activities remain the main means of personal development and self-development, acquisition of new knowledge and formation of competencies. With the development of the information society, education has undergone certain transformations that involve changes in the educational paradigm, methodology and teaching aids. At the same time, there is a demand among students for education that differs from the traditional one [1]. 
The mass spread of coronavirus infection, as well as the introduction of quarantine measures at the state level have significantly changed the organization of the educational process at higher and secondary school. All those changes involved social distancing between the participants of the educational process, development of corresponding regulations, organization of distance learning, etc. Under these conditions, various online learning technologies and tools become relevant [2], including distance education [3], blended learning [4], and massive open online courses (MOOC).

The current trends aimed at democratization and humanization of education caused a transition to personality-oriented and competency-based approaches; they also created conditions for comprehensive and harmonious personal development [5]. As a result, in addition to professional training, a person must have a high level of culture, an ability to communicate constructively, be tolerant of other people, and be a pro-social and active citizen [6]. The use of a set of disciplines within the humanities and natural sciences provides an opportunity to develop all-rounded personality that is well-prepared for active life.

One of the effective tools used for student training in the humanities is information and communication technologies (ICT). They are characterized by a variety of applications, software and technological features. Under the conditions of online learning, rapid development of MOOC and increase in the number of online courses on various topics, there is an urgent need for a quantitative analysis of online courses for training in the humanities.

\section{General research context}

\subsection{Importance of training in the humanities for future specialists}

The realities of life associated with economic, social and man-made transformations in society have significantly affected the requirements for the future specialist training. Today, a graduate of a higher education institution or a working specialist must have professional knowledge and competencies, be capable of self-improvement and selfdetermination [6], be capable to work in a team, have social skills to feel comfortable in society, including the virtual one [7], to demonstrate active social position. The work [8] emphasizes the importance of leadership skills which consist of the ability to motivate other people, to develop self-awareness and critical attitude to your actions.

These abilities and skills are formed to a greater extent during studies at a higher education institution or through self-educational activities. According to the existing trends in the future specialist training, one of the university main tasks is the comprehensive development of students' professional, psychological, moral and aesthetic qualities and abilities. Whereas professional competencies are formed in the process of studying professional disciplines and performing practical activities, the general qualities of personality develop through training in the humanities. 
At the general level, training in the humanities affects the level of personal culture [9] of any specialist. In addition, it is important for the formation of professional competencies in specialists whose activities involve communication and interaction with people.

The formation of professional competencies in the process of training in the humanities can be represented as a model. In the work [6] it is noted that it should look like a multilevel didactic structure containing the content, principles, methods, relevant technologies, and other components. Much attention is paid to the methodological support which is considered at the methodological (concept), theoretical (basic provisions and terminological apparatus) and methodological (interrelated methods and techniques of professional competencies) levels. Also, the effectiveness of training in the humanities is influenced by scientific and methodological support [10] which consists of scientific fundamentals and methods of student culture development, as well as methods of monitoring the process of organization and implementation of training in the humanities, approaches and methods used to improve its content.

The student training in the humanities during their professional studies should comply with the following principles: personal priorities (personality-oriented approach); goal setting and its consistent implementation; labor productivity; reflectivity; self-development; multivariance; variety of influences; fundamentalism [9]. The effective development of the components for training in the humanities depends on social factors, the national social order for high-quality professionals, as well as on taking into account the needs and abilities of students, specific features of their psychological and pedagogical training [11] while studying socio-humanitarian disciplines.

The specifics of training in the humanities for students of certain specialties (including natural sciences and technical ones) should be taken into consideration when it comes to the content of socio-humanitarian disciplines, as well as to the methods and forms of their teaching. In Ukraine, the socio-humanitarian disciplines include philosophy, Ukrainian, foreign language for professional purposes, sociology, psychology, jurisprudence, etc. These educational components deal with processing and reproduction of theoretical information, activation of mental processes, communication between students and teachers, etc. All the disciplines are included either in the normative or variable block of the curriculum. The disciplines of the normative block are obligatory for study. The disciplines of free choice can be chosen by students on the basis of their own preferences. Thus, the individual educational trajectory of each student is formed and conditions for their self-realization are created.

The means of training in the humanities are interactive [12] and multimedia [5] technologies, active teaching methods [13], electronic textbooks [14]. Regarding the organization of the educational process with the help of ICT, training in the humanities can be provided with the help of distance and blended forms of learning.

The traditional system of education involves mastering socio-humanitarian disciplines through lectures, seminars and practical classes, independent work of students (educational and scientific) [11]. Electronic textbooks are considered a bright visual tool that can be used during work in the classroom and independent work. In addition to the same structural elements (theoretical material, questions for self-preparation, literature for self-reading, tests), electronic textbooks for certain disciplines have specific 
structural elements. For example, an electronic textbook on History of Music [5] consists of such components as music files, multimedia presentations, music quiz, bibliography of composers, etc. The use of this textbook promotes the development of students' knowledge of music, musical and educational culture. Specific educational components of the electronic textbook on Ukrainian literature [14] are literary texts for reading, excerpts from videos, presentations about the authors' work, audio files containing songs and poems. The use of this textbook will develop civic competence, artistic taste, and creativity.

In the work [15] it is noted that the introduction of elements of inverted learning and project method in the educational process provides students with the opportunity to increase their own initiative, realize the work effectiveness and implement its results in the learning process. Researchers have proven the effectiveness of using video lectures, electronic textbooks, thematic Internet-communities for training in the humanities in the conditions of blended learning. In order to ensure distance learning, there are learning management systems (LMS), in particular Moodle, which have proven their efficiency. With their help, teachers can create online courses on the disciplines of the normative or variable block and effectively organize students' socio-humanitarian training [13]. In addition to the courses presented on distance learning systems, there is a possibility to use other electronic educational resources, for instance MOOC, in the educational process.

\subsection{Specific features of massive open online courses}

The phenomenon of MOOC attracts the attention of academic and educational community due to its popularity and ability to provide distance education. An analysis of empirical studies published in peer-reviewed journals is reflected in [16] (2008-2015, 362 articles), [17] (2008-2016, 40 relevant studies), [18] (2012-2017, 219 articles). Most of the studies concerned the use of MOOC in education and information technology. At the same time, three times less research works have been devoted to the use of MOOC in the Humanities and Arts [18].

The main scientific issues studied in these research works were: advantages of using MOOC; review of online MOOC platforms; educational content and quality of online courses; difficulties that may arise when using MOOC [16]; development of legal support related to the availability of online education; means and methods of receiving feedback from users; profiling students [17] etc.

Like any technology, MOOC is characterized by a list of advantages and some issues that need to be addressed. The advantages include their mass character, accessibility [19], tuition fees [17], social independence, and an opportunity to obtain a certificate. From the standpoint of social impact on the individual, MOOC contribute to the democratization of education, they provide online learning, allow you to monitor the effectiveness of educational activities; based on the analysis performed they allow you to make appropriate adjustments to technological solutions and educational content [1]. 
The problematic issues related to the use of MOOC are:

- a significant part of online courses imitates the traditional educational paradigm which is characterized by passive participation of students and little help from teachers [16];

- lack of direct communication between students and instructors / course developers [20]. It can lead to a decrease in motivation to complete the online course;

- possible problems when displaying online courses on various digital gadgets [21].

The problematic issues related to the use of MOOC are solved in different ways. The work [22] analyzes some pedagogical practices of effective learning with the help of MOOC. The author analyzed the content of courses, means of interaction between students and instructors, educational tasks, means of progress assessment, etc.

The effectiveness of MOOC in the educational process depends on the support of the teacher [16], social interaction and face-to-face meetings with students [3] throughout the online course. Interaction between students and the teacher when working with MOOC can take place while choosing a specific platform and online course; it can be seen in information and methodological support, discussion of the proposed educational material, etc. In addition, group work on the same problem (in this case it can be a learning topic within the same academic group) brings participants together, develops a sense of belonging to a common cause. At the same time, attention should be paid to the training of teachers who will work as instructors [23].

The student himself and his personal qualities have a great influence on the effectiveness of online learning. In this context, the factors influencing the effectiveness of MOOC could be:

- students' satisfaction in taking online courses;

- developed informative competence and independence [20];

- high level of motivation to acquire new knowledge. The work [21] studies the influence of motivation and behavior on the model of participation and learning success with the help of MOOC.

Despite the help of teachers, the student himself must be motivated to take the course. The main reasons for using MOOC include additional information on subjects taught at an educational institution, development of additional competencies within one's own professional activities, a high level of cognitive interest and the desire to obtain a certificate.

MOOC platforms offer a variety of courses to gain new knowledge and increase your competitiveness. The research by [22], [24] analyzed online courses on natural sciences and humanities according to various aspects. The research by S. Braun et al [25] dealt with the introduction of MOOC in technical courses. The effectiveness of online learning in the humanities is analyzed in [2], [26]. Regarding training in the humanities, MOOC were used in the process of learning a foreign language [20], digital entrepreneurship [27], writing skills improvement [28], [29] etc. 


\section{$3 \quad$ Methodology}

The purpose of the study is to provide a quantitative analysis of online courses on various platforms that can be used for training students and other users in the humanities.

The selection of online platforms was based on such criteria as: prevalence, availability of courses on the humanities, regional context. The most popular MOOC are FutureLearn, FUN [1], Coursera, EdX [16], Udacity [21]. Among the Ukrainian MOOC the most famous are Prometheus, EdEra, OUM [30]. Taking into account the previous research works and our own practical experience, we have chosen three well-known platforms such as Coursera, Udemy, Edx and three Ukrainian-language platforms such as OUM, Prometheus, EdEra for our research.

The quantitative analysis of online courses was conducted as of October 2021. For the quantitative analysis of courses on the Coursera platform, we selected popular courses for students from the sections "Humanities and Arts" and "Language Learning".

The selection of online courses on the Udemy platform was based on online courses in the subcategories "Humanities", "General Sciences", "Language", and "Other Academic Disciplines". Separate topics of "Psychology" and "Critical Thinking" are duplicated in the two categories of "Humanities" and "General Sciences". Therefore, they were taken into account only once in the calculation. Also, during the calculation we did not take into account the online courses on "Statistics" ( 258 courses) which can be found in the "Humanities" section.

For the quantitative analysis of courses on the Edx platform, we chose courses from the sections "Language" and "Humanities". Online courses on epidemics (14 courses), fashion ( 6 courses), and human anatomy (15 courses), which are also presented in the "Humanities" section, were not included in the quantitative analysis either.

As for the Ukrainian-language platforms, the quantitative analysis of online courses was based on the authors' practical experience.

\section{$4 \quad$ Results}

\subsection{General characteristics of the selected MOOC}

The total number of online courses for students on the Coursera platform is 3,900. They allow students to gain knowledge and develop skills in various areas. You can study on the platform for free or with a minimum fee paid for courses or certificates. In particular, minimum tuition costs are offered to students who register on the portal for the first time.

On the Coursera platform each online course contains information about the project, teachers, course program, course reviews, registration parameters and answers to frequently asked questions. Upon successful completion of the course, users can receive a certificate. They can use the "Share" option and tell their friends, family, and interested employers about their success. The Coursera users also have the opportunity to study 
by bachelor's and master's degree programs. Upon successful completion of the program, students receive a diploma.

The Udemy online platform gives students the opportunity to choose the right online course and gain new knowledge. This resource is completely commercial. Compared to other online platforms, it contains the largest number of courses which are divided into 13 categories: development (10,000 courses), business (10,000 courses), finance (6,549 courses), information technology and software (10,000 courses), office software (4397 courses), personal growth (10000 courses), design (10000 courses), marketing (8508 courses), lifestyle (6769 courses), photography and video (2666 courses), health and fitness (7841 courses), music $(4,404)$, educational and academic disciplines $(10,000$ courses). Each category consists of subcategories (from 5 to 16). Each subcategory is divided into a different number of topics (from 8 to 9). In turn, each topic contains more than 12 courses.

The Edx online platform offers 3,077 free courses. The platform is financially supported by the payment for the certificate which the user can receive after successful completion of the course. The main advantages of the Edx platform include the availability of certified courses, courses to obtain a profession, bachelor's and master's degree programs, MicroMasters programs (courses for university graduates who are interested in additional education).

All Edx online courses are divided into 6 blocks: information technology (599 courses); business management (697 courses); engineering (203 courses); Datascience (298 courses); language (134 courses); humanities (177 courses). Each course which is presented in the rubricator contains brief information about the course, basic knowledge, curriculum, and teachers. More detailed information about the course is available on the online course page. The user can learn about the terms of training, the level of the course, its cost, about the institution that is the developer of the course, the level of study, language of instruction, type of course, etc.

In addition to the considered English-language MOOC, such Ukrainian-language online platforms as Edera, OUM, Prometheus are popular in Ukraine. They were developed not so long ago (in 2014). So far, they have a small number of online courses: 64 (Edera), 70 (OUM), 148 (Prometheus). The courses are developed by teams of authors, teachers of higher educational institutions, charitable foundations, international and public organizations. It indicates a stable interest of Ukrainian developers in online education. Basically, Ukrainian MOOC envisage a basic goal, similar to foreign ones, that is to offer a possibility for everyone who wishes to develop their own competencies and gain new knowledge.

\subsection{Data analysis}

On the Coursera platform the category "Humanities and Arts" contains courses on the following disciplines: history -39 courses, philosophy -36 courses, music and art -29 courses. The category "Language Learning" includes online courses to study English ( 85 courses) and other languages ( 39 courses). The total number of online humanities courses is 228 (Table 1). 
Table 1. Number of online humanities courses on the Coursera platform

\begin{tabular}{|c|c|c|c|c|}
\hline Group of disciplines & Disciplines & Fee-paying & Free of charge & Total \\
\hline \multirow{4}{*}{ History } & Modern history & 3 & 7 & 10 \\
\hline & Ancient history & 0 & 7 & 7 \\
\hline & History in the Western world & 2 & 10 & 12 \\
\hline & History of the Middle East & 1 & 9 & 10 \\
\hline \multicolumn{2}{|l|}{ Total } & 6 & 33 & 39 \\
\hline \multirow{3}{*}{ Philosophy } & More Philosophy Courses & 1 & 11 & 12 \\
\hline & $\begin{array}{c}\text { Finish a Philosophy in Course in Under } \\
24 \text { Hours }\end{array}$ & 1 & 11 & 12 \\
\hline & Beginner Philosophy Courses & 1 & 11 & 12 \\
\hline \multicolumn{2}{|l|}{ Total } & 3 & 33 & 36 \\
\hline \multirow{5}{*}{ Music and Art } & Literary creativity & 2 & 3 & 5 \\
\hline & $\begin{array}{l}\text { Principles and practice of UI / UX de- } \\
\text { sign }\end{array}$ & 11 & 0 & 11 \\
\hline & Photography & 3 & 0 & 3 \\
\hline & Create music & 2 & 1 & 3 \\
\hline & Virtual tours of museums & 5 & 2 & 7 \\
\hline \multicolumn{2}{|l|}{ Total } & 23 & 6 & 29 \\
\hline Learning English & Grammar, Speaking, Business English & 23 & 62 & 85 \\
\hline \multicolumn{2}{|l|}{ Total } & 23 & 62 & 85 \\
\hline \multirow{6}{*}{$\begin{array}{l}\text { Learning other lan- } \\
\text { guages }\end{array}$} & French & 0 & 1 & 1 \\
\hline & Spanish & 5 & 0 & 5 \\
\hline & Korean & 5 & 1 & 6 \\
\hline & Russian & 12 & 0 & 12 \\
\hline & Chinese & 8 & 5 & 13 \\
\hline & Japanese & 2 & 0 & 2 \\
\hline \multicolumn{2}{|l|}{ Total } & 32 & 7 & 39 \\
\hline \multicolumn{2}{|c|}{ Total number of online courses } & 87 & 141 & 228 \\
\hline
\end{tabular}

As we can see from Table 1, the online courses which belong to the group of disciplines "History" and "Philosophy" are mostly free $(84.6 \%$ and $91.6 \%$ of courses respectively). This sample of free humanities courses proves the affordability of online education which provides opportunities for self-development and self-study.

The online courses which belong to the group of disciplines "Music and Art" are mostly fee-paying (79.3\%). There are no free courses on such disciplines as "Principles and Practice of UI / UX Design" and "Photography". It might be explained by the demand for these activities which are of practical importance. In this context, it should be understood that MOOC allow students to gain new knowledge and to form new competencies. In the future, the acquired knowledge and certificates may be needed while taking examinations on the similar disciplines, or looking for employment, etc.

With regard to online language courses, it can be seen that the English language courses are mostly free $(72.9 \%)$. This feature is very useful for the Ukrainian-speaking 
region, as it allows you to learn the international language for free. At the same time, most online courses for learning other languages are fee-paying (82\%).

In general, $61.8 \%$ of online humanities courses on the Coursera platform are free.

On the Udemy platform, the online humanities courses are presented in the section "Educational and academic disciplines". This section is divided into subcategories "Humanities" (1237), "General Sciences" (494), "Language" (2725), "Other academic disciplines" (251). The total number of presented humanities courses is 4,295 online courses (Table 2).

Table 2. Number of online humanities courses on the Udemy platform

\begin{tabular}{|c|c|c|}
\hline Section & Topics & Number of courses \\
\hline \multirow{8}{*}{ Humanities } & Christianity & 168 \\
\hline & The Bible & 253 \\
\hline & English Literature & 68 \\
\hline & Psychology & 354 \\
\hline & Creative writing & 115 \\
\hline & History of Art & 121 \\
\hline & Philosophy & 100 \\
\hline & Critical Thinking & 58 \\
\hline \multicolumn{2}{|l|}{ Total } & 1237 \\
\hline \multirow{4}{*}{ General Sciences } & Psychology & 354 (recurrence) \\
\hline & Critical Thinking & 58 (recurrence) \\
\hline & Child Psychology & 52 \\
\hline & Social Psychology & 30 \\
\hline \multicolumn{2}{|l|}{ Total } & 82 \\
\hline \multirow{9}{*}{ Language } & English & 905 \\
\hline & Spoken English & 222 \\
\hline & English Grammar & 367 \\
\hline & English Vocabulary & 144 \\
\hline & Spanish & 303 \\
\hline & French & 263 \\
\hline & German & 251 \\
\hline & Sign language & 43 \\
\hline & Japanese & 227 \\
\hline \multicolumn{2}{|l|}{ Total } & 2725 \\
\hline \multirow{4}{*}{$\begin{array}{l}\text { Other academic disci- } \\
\text { plines }\end{array}$} & Proofreading & 11 \\
\hline & Academic writing & 147 \\
\hline & Punctuation & 18 \\
\hline & Belles-lettres & 75 \\
\hline \multicolumn{2}{|c|}{ Total } & 251 \\
\hline \multicolumn{2}{|c|}{ Total number of online courses } & 4295 \\
\hline
\end{tabular}


According to Table 2, most online courses are presented in such sections as "Language" (2,725 courses) and "Humanities" (1,237 courses) which is $63.4 \%$ and $28.8 \%$ respectively of the total number of online courses on the Udemy platform. The maximum number of courses to study English (1,638 courses) is $38.1 \%$ of the total number of the humanities courses on this platform. The number of online courses for learning other languages ranges 227-303. In the "Language" category, the online courses to study sign language (43 courses) should be considered separately as they do not involve speaking.

On the Edx platform, the online humanities courses are presented in such sections as "Language" (134 courses) and "Humanities" (67). The total number is 201 online courses (Table 3 ).

Table 3. Number of online humanities courses on the Edx platform

\begin{tabular}{|c|c|c|}
\hline Title of the section & Thematic category & Number of courses \\
\hline \multirow{10}{*}{ Language } & Chinese & 31 \\
\hline & Chinese as a second foreign language & 8 \\
\hline & English & 21 \\
\hline & English as a second foreign language & 10 \\
\hline & Grammar & 8 \\
\hline & Italian & 6 \\
\hline & Japanese & 20 \\
\hline & Sign language & 6 \\
\hline & Spanish & 5 \\
\hline & Writing & 19 \\
\hline \multicolumn{2}{|l|}{ Total } & 134 \\
\hline \multirow{7}{*}{ Humanities } & Art courses & 9 \\
\hline & Child development courses & 5 \\
\hline & History courses & 19 \\
\hline & Literature courses & 11 \\
\hline & Psychology courses & 13 \\
\hline & Public speaking courses & 3 \\
\hline & Shakespear courses & 7 \\
\hline \multicolumn{2}{|l|}{ Total } & 67 \\
\hline \multicolumn{2}{|c|}{ Total number of online courses } & 201 \\
\hline
\end{tabular}

As Table 3 shows, on the Edx platform most online courses (66.7\%) are devoted to language learning. Moreover, more attention is paid to the study of Chinese (39 courses), English (31 courses) and Japanese (20 courses) which is respectively $19.4 \%$, $15.4 \%, 9.9 \%$ of the total number of the humanities courses on the platform.

There are no clear online courses in language, literature, art, philosophy and religion on the OUM platform. This is due to the fact that the purpose of the platform is to provide educational content for the public sector. On this platform, we can distinguish only 15 humanities courses with the following titles: "Introduction to critical thinking", 
"Personal and social in the light of classical texts", "Sustainable development: a new philosophy of thinking", "School of effective thinking" and others.

On the online platform Prometheus there is a section "English language" which contains 6 courses for students with different levels of training (A1, A2, for journalists, for career growth, etc.). The section "Advanced training" also contains 6 courses which could be referred to the humanities: "Ukrainian literature. Meaningful and rethought", "Science of everyday thinking", "Design-thinking at school", "Media literacy for educators", "Critical thinking for educators" and other courses. In the section "Preparation for EIE (external independent evaluation)" you can select 1 course in the Ukrainian language and literature and 1 course in History of Ukraine. The presented courses allow students to prepare for external independent evaluation (EIE). The section "Entrepreneurship" contains one humanities course called "Business English". The total number of the humanities courses on the Prometheus online platform is 15 .

The Edera online platform offers online courses for educators. Of the 64 courses on the platform there are only 15 humanities courses. They mainly concern language, literature, philosophy, and psychology. This sample also includes courses for students. It should be noted that they are designed to prepare for the external independent evaluation so they do not provide a certificate.

Summary of the quantitative indicators for popular English and Ukrainian MOOC are shown in Table 4.

Table 4. Total number of online humanities courses

\begin{tabular}{|l|c|c|c|c|c|}
\hline Title of platform & $\begin{array}{c}\text { Total number } \\
\text { of courses }\end{array}$ & $\begin{array}{c}\text { Number of courses } \\
\text { in the humanities }\end{array}$ & Fee-paying & $\begin{array}{c}\text { Free of } \\
\text { charge }\end{array}$ & $\begin{array}{c}\text { \%o of total } \\
\text { number }\end{array}$ \\
\hline Coursera & 3,900 & 228 & + & + & 5.8 \\
\hline Udemy* & $10,000+$ & 4,295 & + & - & 42.9 \\
\hline Edx & 3,077 & 201 & - & + & 6.5 \\
\hline Total & 16,977 & 4,724 & + & + & 27.8 \\
\hline OUM & 70 & 15 & - & + & 21.4 \\
\hline Prometheus & 148 & 15 & - & + & 10.1 \\
\hline EdEra & 64 & 15 & - & + & 23.4 \\
\hline Total & 282 & 45 & - & + & 15.9 \\
\hline $\begin{array}{l}\text { Total number of } \\
\text { courses }\end{array}$ & 17,259 & 4,769 & + & + & 27.6 \\
\hline
\end{tabular}

* For the Udemy platform a section "Educational and academic disciplines" was chosen.

If we analyze the English-language online platforms (see Table 4), we can see a large number of humanities courses $(4,724$ courses) which is $27.8 \%$ of the total number of online courses $(16,977$ courses) on these platforms. Most humanities courses are presented on the Udemy platform $(4,295$ courses which is $90 \%$ of the total number of humanities courses).

As for online courses on the Ukrainian-language platforms, their share is $15.9 \%$ (45 courses) of the total number of online courses (282 courses) on these platforms. If we 
compare the number of the Ukrainian-language courses (45 courses) with English-language courses $(4,724$ courses), their share is very small comprising $0.95 \%$. At the same time, all courses presented on the Ukrainian-language platforms are free.

\section{Discussions}

Training in the humanities, alongside with the professional training, is an important element of a competitive specialist training for future professional activity. However, during the organization of the educational process, we can observe certain contradictions that require solution.

We can often observe a reduction in the number of socio-humanitarian disciplines or transfer of some of them to the block of electives [13]. This is especially true of natural sciences and technical specialties. Due to the insufficient training in the humanities, the future specialist may fail to sufficiently develop the key competencies that are necessary in today's conditions.

The next contradiction is the significant amount of theoretical information that students need to master when studying the socio-humanitarian disciplines. With a small amount of hours devoted to training in the humanities, the study of educational material is sometimes reduced to the reproduction of the information offered by the teacher. At the same time, much less attention is paid to interactive teaching methods and group work.

These contradictions highlight the need to change approaches to the selection of educational components of the humanities, as well as approaches to their teaching and using new educational technologies that meet the key competencies of future professionals [6] in accordance with the chosen specialty taking into account approved training standards for specialists in a particular field.

Most changes in the humanities are determined by technical and technological factors [11], as well as by the increased requirements for modern professionals' training. Despite the fact that the traditional system of education which provides face-to-face communication remains quite influential [4], there is a need to use ICT and new pedagogical technologies.

One of the best ways to combine traditional learning and online education while studying the humanities is to use blended learning [24]. At the same time, innovative educational technologies, in particular "Flipped learning" technology, require an increase in students' level of motivation for independent learning, as well as the share of their autonomy in the process of mastering disciplines. As a result, not all students seek for new forms of learning and ways to acquire knowledge [15]. In addition, to ensure productive blended learning in classrooms, it is necessary to provide a stable Internet connection [28].

In our opinion, close cooperation between the developers of online courses and higher education institutions will lead to positive results. It is important to give MOOC a certain official status, to create legal norms for their use and adhere to them [17], to take into account certificates of online courses at the level of enrolment in certain dis- 
ciplines. This task is successfully solved within the autonomy of higher education institutions through the development of appropriate regulations on the recognition of nonformal education. In turn, online courses developers are encouraged to pay attention to creating educational content in accordance with the needs and interests of students, to increase interactivity and to provide stronger feedback between students and teachers [20].

\section{Conclusion}

Thus, a modern specialist training involves acquisition of professional and general competencies. Professional training is achieved through the study of professional disciplines. General competencies are usually formed in the process of studying the sociohumanitarian disciplines. The means of training in the humanities can be active teaching methods, ICT (multimedia technologies, electronic textbooks, various online resources), etc.

Numerous scientific papers devoted to massive open online courses testify to their relevance. MOOC are especially relevant in the conditions of a pandemic when there is a need to provide the educational process with the help of remote technologies without personal communication. The specific feature of MOOC is the opportunity for everyone interested to develop their own competencies, both at the level of self-development and within the study of particular disciplines.

The most popular MOOC that have been used for the quantitative analysis of online courses are Coursera, Udemy, Edx (English-language resources) and OUM, Prometheus, EdEra (Ukrainian-language online platforms). On the MOOC platforms selected for the analysis, users can get an access to 4,769 online courses (either free or feepaying) which is $27.4 \%$ of the total number of analyzed courses.

Most online humanities courses are presented on the Udemy platform (4,295 courses which is $90 \%$ of the total number of humanities courses). The fewest number of online humanities courses are presented on the Ukrainian-language MOOC platforms (a total of 45 courses). As a result, developers of the EdEra, Prometheus, and OUM platforms are recommended to significantly increase the number of courses without reducing their quality.

Among the disciplines for training in the humanities which are presented in the form of online courses on the considered MOOC platforms, we would like to mention history, philosophy, music, Art (Coursera), religion, psychology, history, Art, literature (Udemy), history, literature, psychology, rhetoric (Edx), literature, Art, philosophy, religion (OUM), literature, history (Prometheus), literature, philosophy, psychology (Edera). The same direction for all the MOOC is language learning. This is quite logical since communication between people is very important for interaction and communication. 


\section{$7 \quad$ References}

[1] De Rosa, R. (2018). A research agenda on MOOCS: the perspective of social sciences. Italian Journal of Educational Technology, 26(2): 54-67. https://doi.org/10.17471/24994324/993

[2] Adedoyin, O., and Soykan, E. (2020). Covid-19 pandemic and online learning: the challenges and opportunities. Interactive Learning Environments, 1-13. https://doi.org/10. $\underline{1080 / 10494820.2020 .1813180}$

[3] Santos, J., De Jesus, L. F., Sealmoy, R. R., and Fajardo, R. R. (2020). Online Distance Learning Amidst COVID-19. International Journal of Educational Research and Innovation, 15: 291-304. https://doi.org/10.46661/ijeri.5271

[4] Alsarayreh, R. (2020). Using blended learning during COVID-19. Cypriot Journal of Educational Sciences, 15(6): 1544-1556. https://doi.org/10.18844/cjes.v15i6.5298

[5] Zhuravleva, O., and Veselova, O. (2020). Multimedia technologies in humanitarian training of a teacher musician. SHS Web of Conferences, 87. https://doi.org/10.1051/ $\underline{\text { shsconf } / 20208700110}$

[6] Nabiyeva, A. R., et. al. (2015). Pedagogical conditions of university students professional core competencies formation in the process of humanitarian training. Journal of Sustainable Development, 8(6): 60-68.

[7] Sharov, S., Vorovka, M., Sharova, T., and Zemlianska, A. (2021). The Impact of Social Networks on the Development of Students' Social Competence. International Journal of Engineering Pedagogy, 11(3): 84-98. https://doi.org/10.3991/ijep.v11i3.20491

[8] Bollettino, V., Brown, K., Schwartz, S., and Burnham, G. (2019). Humanitarian Leadership. Social Science Protocols, 2: 1-12. https://doi.org/10.7565/ssp.2019.2652

[9] Kochneva, L. V., et. al. (2018). Humanitarian component of professional training as factor of increasing student cultural level. Espacios, 39(17): 23-36. https://doi.org/10.5281/ze$\underline{\text { nodo. } 1240395}$

[10] Mukhametzyanova, L. Y., et. al. (2018). Culture-oriented component scientific and methodical support of students' humanitarian training in university. XLinguae, 11(1): 230-241. https://doi.org/10.18355/x1.2018.11.01.19

[11] Gilmeeva, R. K., et. al. (2017). Mechanisms for designing students' humanitarian training as of pedagogical system. Eurasian Journal of Analytical Chemistry, 12(7): 1117-1126. https://doi.org/10.12973/ejac.2017.00237a

[12] Yekimov, S., et. al. (2020). Some problems of humanitarian training of future specialists in pedagogical specialties using interactive technologies. Journal of Physics: Conference Series, 1691. https://doi.org/10.1088/1742-6596/1691/1/012221

[13] Popenko, N. V. (2020). Socio-Humanitarian Training Arrangement Technology Implementation for the Future Masters of Natural Specialties under the Distance Learning Conditions. Engineering and Educational Technologies, 8(1): 19-31. https://doi.org/10. 30929/2307-9770.2020.08.01.02

[14] Sharov, S., Filatova, O., and Sharova, T. (2020). The development of an online platform for studying Ukrainian literature. TEM Journal, 9(3): 1171-1178. https://doi.org/10.18421/ tem $93-43$

[15] Nazarenko, H. A., Lomakina, H. I., and Kolgan, T. V. (2018). Formation of democratic confidence and self-awareness of future educational staff of preschool education. Journal of Social Sciences Research, 5: 522-528. https://doi.org/10.32861/jssr.spi5.522.528

[16] Zawacki-Richter, O., Bozkurt, A., Alturki, U., and Aldraiweesh, A. (2018). What research says about MOOCs - An explorative content analysis. International Review of Research in Open and Distance Learning, 19(1): 242-259. https://doi.org/10.19173/irrodl.v19i1.3356 
[17] Sanchez-Gordon, S., and Lujan-Mora, S. (2018). Research challenges in accessible MOOCs: a systematic literature review 2008-2016. Universal Access in the Information Society, 17(4): 775-789. https://doi.org/10.1007/s10209-017-0531-2

[18] Al-Rahmi, W., et. al. (2019). Massive Open Online Courses (MOOCs): Data on higher education. Data in Brief, 22: 118-125. https://doi.org/10.1016/j.dib.2018.11.139

[19] Lowenthal, P., Snelson, P., and Perkins, C. (2018). Teaching massive, open, online, courses (MOOCs): Tales from the front line. International Review of Research in Open and Distributed Learning, 19(3). https://doi.org/10.19173/irrodl.v19i3.3505

[20] Shalatska, H. M. (2018). The efficiency of MOOCs implementation in teaching English for professional purposes. Information Technologies and Learning Tools. 66(4): 186-196. https://doi.org/10.33407/itlt.v66i4.2106

[21] Gamage, D., Perera, I. and Fernando, S. (2020). Exploring MOOC User Behaviors Beyond Platforms. International Journal of Emerging Technologies in Learning, 15(8): 161-179. https://doi.org/10.3991/ijet.v15i08.12493

[22] Toven-Lindsey, B., Rhoads, R. A. and Lozano, J. B. (2015). Virtually unlimited classrooms: Pedagogical practices in massive open online courses. The internet and higher education. 24: 1-12. https://doi.org/10.1016/j.iheduc.2014.07.001

[23] Albelbisi, N., Yusop, F. D., and Salleh, U. K. M. (2018). Mapping the factors influencing success of massive open online courses (MOOC) in higher education. Eurasia Journal of Mathematics, Science and Technology Education, 14 (7): 2995-3012. https://doi.org/ $10.29333 /$ ejmste/91486

[24] Larionova, V., Brown, K., Bystrova, T., and Sinitsyn, E. (2018). Russian perspectives of online learning technologies in higher education: An empirical study of a MOOC. Research in Comparative and International Education, 13(1): 70-91. https://doi.org/10.1177/ 1745499918763420

[25] Braun, C., Ebner, M., Fickert, L. H., and Schon, S. (2021). The Online Course as Initial Stage of a Course in Higher Education: Implementation and Evaluation of the Pre-MOOC Concept in a Technical Degree Course. International Journal of Emerging Technologies in Learning, 16(06): 245-258. https://doi.org/10.3991/ijet.v16i06.16617

[26] Jin, L. (2020). Exploring the Determinants of Massive Open Online Courses Reusage Intention in Humanities. 2020 International Conference on Big Data, Artificial Intelligence and Internet of Things Engineering (ICBAIE 2020), pp. 238-241. https://doi.org/10.1109/ icbaie49996.2020.00056

[27] Vorbach, S., Poandl, E. M. and Korajman, I. (2019). Digital Entrepreneurship Education: The Role of MOOCs. International Journal of Engineering Pedagogy. 3(9): 99-111 https://doi.org/10.3991/ijep.v9i3.10149

[28] Jasni, N. S., Hashim, H., Md Yunus, M., and Rahman, S. F. A. (2019). Distance Learning via MOOCs: Improving ESL Learners' Writing Skills. Journal of Physics: Conference Series, 1424. https://doi.org/10.1088/1742-6596/1424/1/012031

[29] Comer, D. (2013). MOOCs offer students opportunity to grow as writers. 7th International Multi-Conference on Society, Cybernetics and Informatics (IMSCI 2013). International Institute of Informatics and Systemics, IIIS, pp. 248-252.

[30] Sharov, S., Pavlenko, A., Sharova, T., Chorna, O. (2021). Analysis of Developers of Online Courses on Ukrainian Platforms of MOOC. International Journal of Emerging Technologies in Learning, 16(5): 201-2133. https://doi.org/10.3991/ijet.v16i05.18581 


\section{Authors}

Sergii Sharov is PhD of Pedagogical Sciences, Associate professor, Associate professor of Department of Computer Sciences, Dmytro Motornyi Tavria State Agrotechnological University, 18, Bogdan Khmelnitsky Ave., Melitopol, 72312, Ukraine. The author's research interests include the use of ICT in high school, massive open online courses, programming, social competence of students. He is also been a member of public organizations "Innovative horizons of Ukraine" and "Ukrainian Educational Research Association.

Oksana Filatova is Doctor of Philological Sciences, Professor, Head of Department of Social Studies and Humanities, Admiral Makarov National University of Shipbuilding, 9, Heroes of Ukraine Ave., Mykolaiv, 54000, Ukraine. The author's research interests include philology and social communication.

Valentyna Biliatska is Doctor of Philological Sciences, Professor of Philology and Language Communication Department, Dnipro University of Technology, 19, Dmytra Yavornytskoho Ave., Dnipro, 49005, Ukraine. Field of interests: history of literature, student training in the humanities.

Nadia Yankova is Doctor of Philological Sciences, Associate Professor of Department of History of Ukrainian Literature, Literary Theory and Creative Writing, Taras Shevchenko National University of Kyiv, 60 Volodymyrska Str., Kyiv, 01033, Ukraine. The academic interest is historical prose, drama, and modern literature.

Article submitted 2021-06-25. Resubmitted 2021-08-16. Final acceptance 2021-08-17. Final version published as submitted by the authors. 